Tropical Journal of Pharmaceutical Research July 2020; 19 (7): 1359-1364

ISSN: $1596-5996$ (print); 1596-9827 (electronic)

(C) Pharmacotherapy Group, Faculty of Pharmacy, University of Benin, Benin City, 300001 Nigeria.

\title{
Z-ligustilide reduces cisplatin-induced nephrotoxicity via activation of NRF2/HO-1 signaling pathways
}

\author{
Xu Chen ${ }^{1,2}$, Yingjie $\mathrm{Cao}^{2}$, Naifeng Guo ${ }^{2}$, Guoyuan Lu ${ }^{1 *}$ \\ ${ }^{1}$ Department of Nephrology, The First Affiliated Hospital of Soochow University, Suzhou, Jiangsu 215006, ${ }^{2}$ Department of \\ Nephrology, Affiliated Hospital of Nantong University, Nantong, Jiangsu 226001, China \\ *For correspondence: Email: luguoyuan947@163.com; Tel: +86-13776061947
}

\begin{abstract}
Purpose: To investigate the effect of Z-ligustilide (Z-lig) on cisplatin-induced nephrotoxicity and examine whether NRF2 signaling mediates the underlying mechanism of action.

Methods: Human proximal tubular epithelial cells (HK-2) were pretreated with 20 or $100 \mu \mathrm{M}$ Z-lig for 2 $h$, followed by $10 \mu \mathrm{M}$ cisplatin treatment for $24 \mathrm{~h}$. Cell viability was measured using (3-(4,5dimethylthiazol-2-yl)-2,5-diphenyltetrazolium bromide (MTT) assay. A commercial kit was used to determine lactate dehydrogenase $(L D H)$ release. Apoptosis was determined by flow cytometry while Western blotting was used to evaluate protein levels. Levels of malondialdehyde (MDA), superoxide dismutase (SOD), glutathione (GSH), and glutathione peroxidase (GSH-Px) were assessed by enzymelinked immunosorbent assay (ELISA).

Results: Cisplatin decreased HK-2 cell viability and increased $L D H$ release, while Z-lig increased cell viability and decreased $L D H$ release in a dose-dependent manner $(p<0.05)$. Moreover, Z-lig reduced cisplatin-induced apoptosis ( $p<0.01$ ), and alleviated cellular oxidative stress caused by cisplatin $(p<$ 0.05). Furthermore, Z-lig activated NRF2/HO-1 signaling in cells treated with cisplatin $(p<0.05)$. Conclusion: Z-lig reduces cisplatin-induced nephrotoxicity via activation of NRF2/HO-1 signaling. Thus, Z-lig is a potential drug for the treatment of nephrotoxicity caused by cisplatin.
\end{abstract}

Keywords: Z-ligustilide, Cisplatin, Nephrotoxicity, Oxidative stress, Apoptosis, Nuclear factor erythroid 2-related factor 2, Heme oxygenase-1

\begin{abstract}
This is an Open Access article that uses a fund-ing model which does not charge readers or their institutions for access and distributed under the terms of the Creative Commons Attribution License (http://creativecommons.org/licenses/by/4.0) and the Budapest Open Access Initiative (http://www.budapestopenaccessinitiative.org/read), which permit unrestricted use, distribution, and reproduction in any medium, provided the original work is properly credited.
\end{abstract}

Tropical Journal of Pharmaceutical Research is indexed by Science Citation Index (SciSearch), Scopus, International Pharmaceutical Abstract, Chemical Abstracts, Embase, Index Copernicus, EBSCO, African Index Medicus, JournalSeek, Journal Citation Reports/Science Edition, Directory of Open Access Journals (DOAJ), African Journal Online, Bioline International, Open-J-Gate and Pharmacy Abstracts

\section{INTRODUCTION}

Cisplatin is a primary chemotherapy drug used to treat various cancers [1]. Nevertheless, nephrotoxicity limits the use of cisplatin [2]. Previous studies revealed that over $30 \%$ of patients present symptoms of acute renal injury following cisplatin administration [3,4]. The mechanism of cisplatin-induced nephrotoxicity is related to many factors, such as cellular oxidative stress, mitochondrial dysfunction, and apoptosis [5]. Oxidative stress is considered to be an important factor leading to cisplatin nephrotoxicity [6]. In some cell types, Nuclear factor erythroid 2-related factor 2 (NRF2) is involved in oxidative stress [7]. 
Activation of the NRF2 signaling pathway may alleviate cisplatin-induced nephrotoxicity [8]. For example, melatonin alleviated cisplatin-induced nephrotoxicity through activation of the NRF2/heme oxygenase-1 (HO-1) pathway [9]. Accumulating evidence suggests that a variety of Chinese herbal extracts, including curcumin, resveratrol, and sulforaphane, serve as NRF2 activators [10-12]. Therefore, these extracts may promote resistance to cisplatin-induced nephrotoxicity by activating the Nrf2 pathway.

Z-Ligustilide (Z-lig), the main phthalide component of medicinal plants in the Apiaceae (Umbelliferae) family, exerts protective effects in diseases of the nervous system [13]. For example, Z-lig decreased cerebral infarct size and brain swelling in rats with focal ischemic injury [13].

Moreover, Wu et al found that Z-lig alleviated oxidative stress induced by ultraviolet $B$ irradiation, reduced release of inflammatory factors via activation of NRF2/HO-1 signaling, and suppressed the Nuclear Factor Kappa B (NF-kB) pathway [14]. These results imply that Zlig also functions as an NRF2 activator. Therefore, Z-lig may alleviate cisplatin-induced nephrotoxicity via NRF2 signaling.

Hence, the goals of the present study were to determine effects of Z-lig on cisplatin-induced nephrotoxicity, and to investigate whether NRF2 signaling mediates its underlying mechanism of action.

\section{EXPERIMENTAL}

\section{Cell culture}

Cells of the human proximal tubular epithelial cell line HK-2 were obtained from American Type Culture Collection, and maintained on Keratinocyte Serum Free Medium plus 10\% fetal bovine serum, $100 \mathrm{U} / \mathrm{mL}$ penicillin, and 100 $\mu \mathrm{g} / \mathrm{mL}$ streptomycin (Gibco, Grand Island, NY, USA), in a $5 \% \mathrm{CO}_{2}$ atmosphere at $37^{\circ} \mathrm{C}$. Cells were pretreated with 20 or $100 \mu \mathrm{M}$ Z-lig for $2 \mathrm{~h}$, followed by $10 \mu \mathrm{M}$ cisplatin treatment for $24 \mathrm{~h}$.

\section{(3-(4,5-Dimethylthiazol-2-yl)-2,5- diphenyltetrazolium bromide (MTT) assay}

Cells were inoculated into 96-well plates. After 24 $\mathrm{h}$ of culture, cells were treated with $20 \mu \mathrm{L}$ of MTT for $4 \mathrm{~h}$. Subsequently, the medium was removed, and $200 \mu \mathrm{L}$ of DMSO (Sigma, St. Louis, Mo, USA) was added to cells to solubilize the formazan product. The absorbance at $490 \mathrm{~nm}$ was measured by a microplate reader.

\section{Assessment of lactate dehydrogenase (LDH) release}

$\mathrm{LDH}$ release from HK-2 cells after cisplatin or Zlig treatments was determined using the CyQUANT LDH Cytotoxicity Assay (Thermo Fisher, Waltham, MA, USA), according to the protocols of the manufacturer. Absorbance at $490 \mathrm{~nm}$ was determined using a microplate reader.

\section{Flow cytometry}

After cisplatin or Z-lig treatments, cells were suspended, centrifuged, resuspended in $1 \times$ binding buffer, and stained with $5 \mu \mathrm{L}$ of Annexin V-FITC and $10 \mu \mathrm{L}$ of PI (BD, San Jose, CA, USA) for $15 \mathrm{~min}$. The proportions of apoptotic cells were determined using flow cytometry (BD, San Jose, CA, USA).

\section{Western blotting}

Cellular proteins were extracted utilizing RIPA buffer (Thermo Fisher, Waltham, MA, USA), and quantified by the BCA method. The lysates were separated by SDS-PAGE and transferred to a PVDF membrane. The membrane was blocked by incubation with $4 \%$ non-fat milk, then probed with anti-Cleaved caspase-3 (1:500), antiCleaved caspase-9 (1:500), anti-NRF2 (1:500), anti-HO-1 (1:500), or anti-GAPDH $(1: 1,000)$ (all from Abcam, Cambridge, UK) for $12 \mathrm{~h}$ at $4^{\circ} \mathrm{C}$. After the washing step, the membrane was incubated with HRP-labeled anti-lgG secondary antibody (Abcam, Cambridge, UK). The blots were visualized using the ECL chemiluminescence kit (Beyotime, Shanghai, China).

\section{Enzyme-linked immunosorbent assay (ELISA)}

After treatment of cells with cisplatin or Z-lig and harvesting, levels of malondialdehyde (MDA), superoxide dismutase (SOD), glutathione (GSH), and glutathione peroxidase (GSH-Px) were determined using ELISA assay kits ( $R$ \& $D$ Systems, Minneapolis, MN, USA), following the protocols of the manufacturer.

\section{Statistical analysis}

The SPSS statistics software (Chicago, IL, USA) was used for statistical analysis of the data. Data are presented as mean \pm standard deviation (SD). The differences among multiple groups were determined by one-way ANOVA. Differences were considered statistically significant at $p<0.05$. 


\section{RESULTS}

\section{Z-lig reduces cisplatin-induced HK-2 cell injury}

To elucidate the effect of Z-lig on nephrotoxicity caused by cisplatin, we first assessed cell viability and $\mathrm{LDH}$ release by HK-2 cells that had been treated with Z-lig or cisplatin. The chemical structure of Z-lig is shown in Figure $1 \mathrm{~A}$. Cisplatin significantly reduced cell viability $(p<0.01$, Figure $1 \mathrm{~B}$ ). However, $20 \mu \mathrm{M}$ and $100 \mu \mathrm{M}$ Z-lig significantly increased the viability of cells treated with cisplatin ( $p<0.01$, Figure $1 \mathrm{~B}$ ). Furthermore, cisplatin treatment led to release of LDH from cells $(p<0.01$, Figure $1 \mathrm{C}$ ). However, $20 \mu \mathrm{M}$ and $100 \mu \mathrm{M}$ Z-lig significantly reduced LDH release $(p<0.05$, Figure $1 \mathrm{C})$. In addition, $100 \mu \mathrm{M}$ Z-lig alone did not alter cell viability or LDH leakage (Figures $1 \mathrm{~B}$ and $\mathrm{C}$ ). These results indicated that Z-lig was nontoxic to the cells, and that Z-lig reduced cellular injury caused by cisplatin.
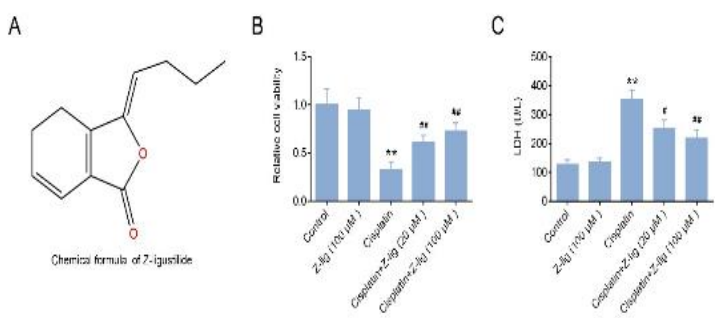

Figure 1: Z-lig reduces cisplatin-induced HK-2 cell injury. A. Chemical structure of Z-lig. B. Cell viability was determined by MTT assay in cells pretreated with $20 \mu \mathrm{M}$ or $100 \mu \mathrm{M}$ Z-lig for $2 \mathrm{~h}$ before stimulation with $10 \mu \mathrm{M}$ cisplatin for $24 \mathrm{~h}$. C. $\mathrm{LDH}$ release from cells that were pretreated with $20 \mu \mathrm{M}$ or $100 \mu \mathrm{M}$ Z-lig for $2 \mathrm{~h}$, followed by treatment with $10 \mu \mathrm{M}$ cisplatin for $24 \mathrm{~h}$; ${ }^{* *} p$ $<0.01$ compared to control; \#p < 0.05 compared to cisplatin; \# $\# 0.01$ compared to cisplatin

\section{Z-lig reduces cisplatin-induced apoptosis of HK-2 cells}

To further investigate the effect of Z-lig on nephrotoxicity caused by cisplatin, apoptosis of cells treated with Z-lig or cisplatin was determined. Flow cytometry revealed increased apoptosis of cells treated with cisplatin $(p<0.01$, Figure 2 A). However, apoptosis of cisplatintreated cells was significantly reduced by either $20 \mu \mathrm{M}$ or $100 \mu \mathrm{M}$ Z-lig ( $p<0.01$, Figure 2). Moreover, levels of cleaved caspase- 3 and cleaved caspase- 9 were significantly increased in cells treated with cisplatin $(p<0.01$, Figure 2 B). In contrast, $20 \mu \mathrm{M}$ and $100 \mu \mathrm{M}$ Z-lig decreased the elevation of cleaved caspase-3 and cleaved caspase- 9 by cisplatin treatment $(p$
< 0.01, Figure 2 B). Thus, Z-lig reduced apoptosis of cells treated with cisplatin.

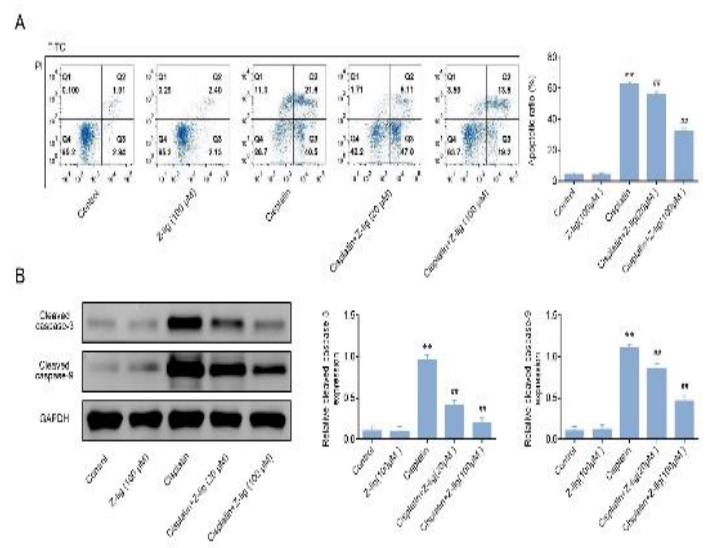

Figure 2: Z-lig suppresses cisplatin-induced apoptosis of HK-2 cells. A. Apoptosis of cells pretreated with 20 $\mu \mathrm{M}$ or $100 \mu \mathrm{M}$ Z-lig for $2 \mathrm{~h}$, followed by treatment with $10 \mu \mathrm{M}$ cisplatin for $24 \mathrm{~h}$, was measured by flow cytometry. B. Levels of cleaved caspase-3 and cleaved caspase- 9 in cells pretreated with $20 \mu \mathrm{M}$ or $100 \mu \mathrm{M}$ Z-lig for $2 \mathrm{~h}$, followed by stimulation with 10 $\mu \mathrm{M}$ cisplatin for $24 \mathrm{~h}$, were determined by Western blot; ${ }^{* *} p<0.01$ compared to control; \#\#p $<0.01$ compared to cisplatin

\section{Z-lig reduces cisplatin-induced oxidative stress in HK-2 cells}

To further study the effect of Z-lig on nephrotoxicity caused by cisplatin, we determined oxidative stress in cells treated with Z-lig or cisplatin. Cells treated with cisplatin showed increased MDA $(p<0.01)$, while pretreatment with either $20 \mu \mathrm{M}(p<0.05)$ or 100 $\mu \mathrm{M}$ Z-lig $(p<0.01)$ decreased this level (Figure 3 A). Cisplatin treatment decreased cellular SOD $(p<0.01)$, while pretreatment with either $20 \mu \mathrm{M}$ $(p<0.05)$ or $100 \mu \mathrm{M}$ Z-lig $(p<0.05)$ increased SOD levels in cisplatin-treated cells (Figure $3 \mathrm{~B}$ ). GSH was also reduced in cisplatin-treated cells $(p<0.01)$, whereas $20 \mu \mathrm{M}$ or $100 \mu \mathrm{M}$ Z-lig increased levels of GSH in cisplatin-treated cells (all $p<0.05$, Figure $3 \mathrm{C}$ ). Moreover, cellular levels of GSH-Px were suppressed by cisplatin $(p<0.01)$, and this effect was diminished by 20 $\mu \mathrm{M}(p<0.05)$ or $100 \mu \mathrm{M} Z$-lig $(p<0.01)$ (Figure 3 D). Hence, Z-lig reduced cellular oxidative stress caused by cisplatin.

\section{Z-lig modulates the NRF2/HO-1 signaling pathway in cisplatin-treated HK-2 cells}

To explain the mechanism of modulation of cisplatin-induced cell injury by Z-lig, we determined apoptosis, cellular oxidative stress, and changes in the activation of NRF2/HO-1 signaling in cells treated with Z-lig or cisplatin. 
Levels of NRF2 and HO-1 expression were slightly increased in cells treated with cisplatin (both $p<0.05$ ), while $20 \mu \mathrm{M}$ or $100 \mu \mathrm{M}$ Z-lig further elevated NRF2 and HO-1 expression in cisplatin-treated cells (all $p<0.05$, Figure 4). Consequently, Z-lig activated NRF2/HO-1 signaling in cisplatin-treated cells.
A

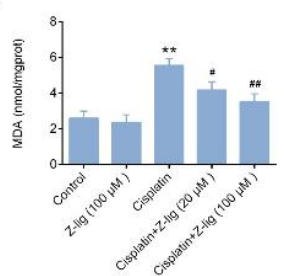

C

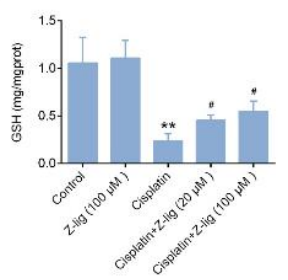

B

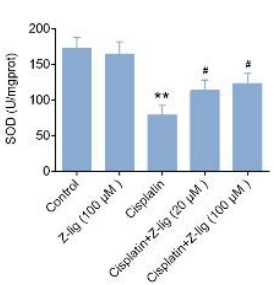

D

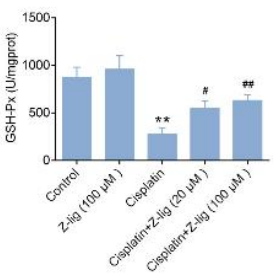

Figure 3: Z-lig inhibits cisplatin-induced oxidative stress in HK-2 cells. A. MDA levels in cells pretreated with $20 \mu \mathrm{M}$ or $100 \mu \mathrm{M}$ Z-lig for $2 \mathrm{~h}$, followed by stimulation with $10 \mu \mathrm{M}$ cisplatin for $24 \mathrm{~h}$, were measured using ELISA. B. SOD levels in cells pretreated with $20 \mu \mathrm{M}$ or $100 \mu \mathrm{M}$ Z-lig for $2 \mathrm{~h}$, followed by treatment with $10 \mu \mathrm{M}$ cisplatin for $24 \mathrm{~h}$, were measured by ELISA. C. Levels of GSH in cells pretreated with $20 \mu \mathrm{M}$ or $100 \mu \mathrm{M}$ Z-lig for $2 \mathrm{~h}$, followed by stimulation with $10 \mu \mathrm{M}$ cisplatin for $24 \mathrm{~h}$, were measured by ELISA. D. Levels of GSH-Px in cells pretreated with $20 \mu \mathrm{M}$ or $100 \mu \mathrm{M}$ Z-lig for $2 \mathrm{~h}$, followed by stimulation with $10 \mu \mathrm{M}$ cisplatin for $24 \mathrm{~h}$, were measured using ELISA; ${ }^{* *} p<0.01$ compared to control; \#p < 0.05 compared to cisplatin; \#\# $<0.01$ compared to cisplatin. All experiments were performed in triplicate
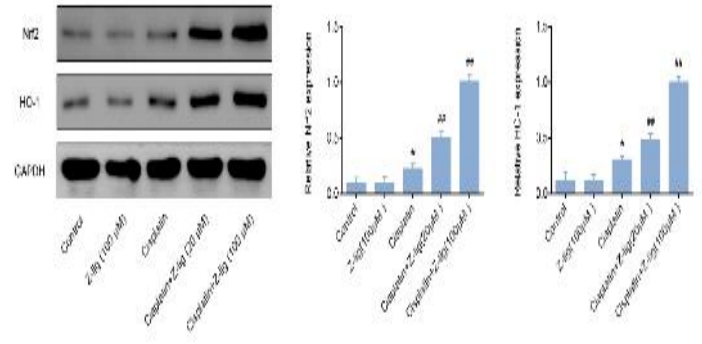

Figure 4: Z-lig activates NRF2/HO-1 signaling in cisplatin-treated HK-2 cells. Levels of NRF2 and HO-1 protein in cells pretreated with $20 \mu \mathrm{M}$ or $100 \mu \mathrm{M}$ Z-lig for $2 \mathrm{~h}$, followed by stimulation with $10 \mu \mathrm{M}$ cisplatin for $24 \mathrm{~h}$, were determined by Western blot; ${ }^{*} p<0.01$ compared to control; ${ }^{* *} p<0.01$ compared to control; $\#$ \# $<0.01$ compared to cisplatin. All experiments were performed in triplicate

\section{DISCUSSION}

Cisplatin is a primary chemotherapy drug for the treatment of various cancers. However, more than $30 \%$ of patients present acute renal injury symptoms following cisplatin treatment $[1,3]$. Therefore, nephrotoxicity induced by cisplatin limits its use in cancer chemotherapy. Hence, it is essential to search for effective drugs to prevent nephrotoxicity.

The present study investigated the protective effect of Z-ligustilide, a phthalide component of medicinal plants in the family Apiaceae (Umbelliferae), on cisplatin-induced nephrotoxicity. We found that Z-lig reversed both the loss of viability and increase in LDH leakage induced in HK-2 cells by cisplatin, consistent with previous studies $[15,16]$. For instance, research by Wu et al also revealed that Z-lig enhanced cell viability and reduced $\mathrm{LDH}$ release in neurons subjected to oxygen-glucose deprivation [15]. Therefore, Z-lig reduces cellular injury caused by cisplatin.

Because apoptosis is among the causes of cisplatin-induced neurotoxicity, we studied the effects of Z-lig on apoptosis induced in HK-2 cells by cisplatin and found that Z-lig reduced cisplatin-induced apoptosis in these cells. Antiapoptotic effects of Z-lig were also proven in neurons treated with Abeta25-35 [17]. In a study conducted by Zhang et al, Z-lig reversed the decrease in neuron viability and the increase in apoptosis caused by Abeta25-35, and prevented Abeta25-35 cytotoxicity [17]. Furthermore, a study by Bunel et al comparing protection against cisplatin toxicity by ferulic acid, Z-lig, and E-lig revealed that Z-lig reduced cisplatin-induced apoptosis [18].

Oxidative stress has been regarded as the critical factor leading to cisplatin nephrotoxicity [6]. The effect of Z-lig in modulating oxidative stress was investigated in a previous study, in which levels of primary indicators of oxidative stress were determined, including MDA, SOD, GSH, and GSH-Px [19]. Z-Lig reversed the cisplatin-induced increase in MDA formation, the reduced GSH level, and the decreased expression of SOD and GSH-Px in that study, in accordance with other previous reports $[14,20]$.

Z-lig also functions as an antioxidant in ischemic brain tissues, suppressing MDA content and elevating SOD, GSH, and GSH-Px [20]. In addition, Wu et al concluded that Z-lig attenuates oxidative stress induced by ultraviolet B [14]. Thus, these results are consistent with reduction of cisplatin-induced oxidative stress by Z-lig. 
NRF2 signaling is known to be involved in oxidative stress [21,22], and activation of this signaling pathway alleviates cisplatin-induced nephrotoxicity $[7,9]$. To study the underlying mechanism of Z-lig protection against cisplatin nephrotoxicity, we investigated activation of NRF2 signaling in cisplatin-treated HK-2 cells and showed that Z-lig activated the NRF2/HO-1 signaling pathway, a result consistent with previous studies $[23,24]$.

Z-lig was shown to alleviate cerebral ischemiareperfusion injury through NRF2/HO-1 activation [23], whereas in human keratinocytes, Z-lig repressed CYP1A1 upregulation caused by benzo(a)pyrene through activation of NRF2 [24]. We conclude that Z-lig activates NRF2/HO-1 signaling in cisplatin-treated cells, and that Z-lig reduces cell injury, apoptosis, and cellular oxidative stress via NRF2/HO-1 activation.

\section{CONCLUSION}

Z-lig attenuates cisplatin-induced nephrotoxicity via activation of NRF2/HO-1 signaling. Thus, Zlig is a potential drug for the therapy of nephrotoxicity caused by cisplatin. However, further studies are required to strengthen this assertion.

\section{DECLARATIONS}

\section{Conflict of interest}

No conflict of interest is associated with this work.

\section{Contribution of authors}

We declare that this work was done by the authors named in this article and all liabilities pertaining to claims relating to the content of this article will be borne by the authors.

\section{Open Access}

This is an Open Access article that uses a funding model which does not charge readers or their institutions for access and distributed under the terms of the Creative Commons Attribution License (http://creativecommons.org/licenses/by/ 4.0) and the Budapest Open Access Initiative (http://www.budapestopenaccessinitiative.org/rea d), which permit unrestricted use, distribution, and reproduction in any medium, provided the original work is properly credited.

\section{REFERENCES}

1. Arany I, Safirstein RL: Cisplatin nephrotoxicity. Semin Nephrol 2003; 460-464.

2. Miller RP, Tadagavadi RK, Ramesh G, Reeves WB. Mechanisms of cisplatin nephrotoxicity. Toxins 2010; 2(11): 2490-2518.

3. Ries F, Klastersky J. Nephrotoxicity Induced by Cancer Chemotherapy With Special Emphasis on Cisplatin Toxicity. Am J Kidn Dis 8(5): 368-379.

4. Kamenik M, Kos D, MÖLLER PETRUN A, Green DW, Zorko N, Mekiš D. Haemodynamic stability during anaesthesia induction with propofol-impact of phenylephrine. A double-blind, randomised clinical trial. Signa vitae 2018; 14(1): 20-26.

5. Ma $Q, X u Y$, Tang L, Yang $X$, Chen $Z$, Wei $Y$, Shao $X$, Shao $X$, Xin Z, Cai B. Astragalus Polysaccharide Attenuates Cisplatin-Induced Acute Kidney Injury by Suppressing Oxidative Damage and Mitochondrial Dysfunction. BioMed Research International 2020; (2020).

6. Cao X, Zhang W, Moore PK, Bian J. Protective Smell of Hydrogen Sulfide and Polysulfide in Cisplatin-Induced Nephrotoxicity. Int J Mol Sci 2019; 20(2): 313.

7. Ma Q. Role of nrf2 in oxidative stress and toxicity. Annu Rev Pharmacol 2013; 53(401-426.

8. Shelton LM, Park BK, Copple IM. Role of Nrf2 in protection against acute kidney injury. Kidney Int2013; 84(6): 1090-1095.

9. Kilic U, Kilic E, Tuzcu Z, Tuzcu M, Ozercan IH, Yilmaz O, Sahin F, Sahin K. Melatonin suppresses cisplatininduced nephrotoxicity via activation of $\mathrm{Nrf}-2 / \mathrm{HO}-1$ pathway. Nutr Metab 2013; 10(1): 7.

10. Zeng $C$, Zhong P, Zhao Y, Kanchana K, Zhang Y, Khan ZA, Chakrabarti S, Wu L, Wang J, Liang G. Curcumin protects hearts from FFA-induced injury by activating Nrf2 and inactivating NF-KB both in vitro and in vivo. J Mol Cell Cardiol 2015; 79: 1-12.

11. Ungvari Z, Bagi Z, Feher A, Recchia FA, Sonntag WE, Pearson K, De Cabo R, Csiszar A. Resveratrol confers endothelial protection via activation of the antioxidant transcription factor Nrf2. Am J Physiol-Heart C 2010; 299(1): H18-H24.

12. Zhang C, Su Z-Y, Khor TO, Shu L, Kong A-NT. Sulforaphane enhances Nrf2 expression in prostate cancer TRAMP C1 cells through epigenetic regulation. Biochem pharmacol 2013; 85(9): 1398-1404.

13. Peng $H-Y$, Du J-R, Zhang G-Y, Kuang X, Liu Y-X, Qian Z-M, Wang C-Y. Neuroprotective effect of Z-ligustilide against permanent focal ischemic damage in rats. Biol Pharm Bull 2007; 30(2): 309-312.

14. Wu Z, Uchi H, Morino-Koga S, Shi W, Furue $M$. Z-ligustilide ameliorated ultraviolet $B$-induced oxidative stress and inflammatory cytokine production in human keratinocytes through upregulation of $\mathrm{N}$ rf2/HO-1 and suppression of NF-K B pathway. Exp Dermatol 2015; 24(9): 703-708. 
15. Wu Xm, Qian Zm, Zhu L, Du F, Yung Wh, Gong Q, Ke Y. Neuroprotective effect of ligustilide against ischaemia-reperfusion injury via up-regulation of erythropoietin and down-regulation of RTP801. Brit $J$ Pharmacol 2011; 164(2): 332-343.

16. Xu W, Yang L, Li J. Protection against $\beta$-amyloid-induced neurotoxicity by naturally occurring Z-ligustilide through the concurrent regulation of p38 and PI3-K/Akt pathways. Neurochem Int 2016; 100: 44-51.

17. Zhang $M, Y u Y, D u$ J. Protective effects of Z-ligustilide against cytotoxicity induced by Abeta25-35 in neuron cells. Sichuan da xue xue bao Yi xue ban 2012; 43(1): 34-37.

18. Bunel V, Antoine $M-H$, Nortier J, Duez P, Stévigny C. Nephroprotective effects of ferulic acid, Z-ligustilide and E-ligustilide isolated from Angelica sinensis against cisplatin toxicity in vitro. Toxicol in vitro 2015; 29(3): 458-467.

19. Todorova I, Simeonova G, Kyuchukova D, Dinev D, Gadjeva V. Reference values of oxidative stress parameters (MDA, SOD, CAT) in dogs and cats. Comp Clin Pathol 2005; 13(4): 190-194.
20. Kuang X, Yao Y, Du J, Liu Y, Wang C, Qian Z. Neuroprotective role of Z-ligustilide against forebrain ischemic injury in ICR mice. Brain Res 2006; 1102(1): 145-153.

21. Wang S-x, Liang P-y, Han Y-n, Zhou B-f, Chen J-h. Glechoma longituba (Lamiaceae) alleviates apoptosis in calcium oxalate-induced oxidative stress in kidney proximal tubule epithelial cell line, HK-2. Trop J Pharm Res 2018; 17(2): 225-232.

22. Zhang $D$, Hou L, Peng $W$. Tangeritin attenuates oxidative stress, apoptosis and inflammation in cadmium-induced cardiotoxicity in rats by activating Nrf2 signaling pathway. Trop J Pharm Res 2018; 17(12).

23. Peng $B$, Zhao $P$, Lu Y-P, Chen M-M, Sun $H$, Wu X-M, Zhu L. Z-ligustilide activates the Nrf2/HO-1 pathway and protects against cerebral ischemia-reperfusion injury in vivo and in vitro. Brain Res 2013; 1520: 168-177.

24. Wu Z, Uchi H, Morino-Koga S, Nakamura-Satomura A, Kita K, Shi W, Furue M. Z-Ligustilide inhibits benzo (a) pyrene-induced CYP1A1 upregulation in cultured human keratinocytes via ROS-dependent Nrf2 activation. Exp Dermatol 2014; 23(4): 260-265. 